\title{
Services for Younger Sufferers of Alzheimer's Disease
}

\author{
D. D. R. WILLIAMS
}

The gradual development of comprehensive psychiatric services for the elderly was brought about by a number of factors. One of these was the necessity for a targeted service for patients with dementia. This perspective was reinforced in 1982 by the publication of The Rising Tide, an influential report describing the need to take action on the problems of age-related psychiatric disorder with the increasing proportion of old people in the community (NHS Health Advisory Service, 1982). Following its publication, many more new psychogeriatric services were established. By the end of that decade most of the country was serviced by specialist led psychogeriatric teams. The vast majority of these were comprehensive services dedicated to patients over the age of 65 .

As these new services were being inaugurated, a small number of psychiatrists were very conscious that younger sufferers with pre-senile dementia were becoming orphaned in no-man's land. The lack of a coordinated service for this group has continued with the exception of a few pioneering examples. Newson-Smith (1983) described the Hamble Unit at Knowle Hospital, Fareham, which was established in 1973. This was a specialised unit for younger persons with brain damage which had been acquired in adult life as a result of trauma or illness. These included individuals with Alzheimer's disease. Previously, these patients had been placed in long-stay and psychogeriatric wards. Old age psychiatrists have been sympathetic to the plight of these patients, but the distress caused by the generation gap remains a continuing problem. Younger sufferers with Alzheimer's disease are usually more aware of their illness. They feel more frustrated by their limitations and require more sophisticated management to explain what is happening to them. Newson-Smith (1983) described uncertainty about the type of service needed and to whom the medical responsibility belongs.

Stout (1987), a psychogeriatrician in Manchester, described how he had provided a service for presumed pre-senile dementias of all types. This was only possible because he was able to utilise vacant beds in a large mental hospital, Prestwich. With the eventual closure of this hospital he was uncertain how this specialised service could be maintained, particularly as there were no guidelines to suggest the exact level of provision required.
A further important perspective on Alzheimer's disease in the younger age group is published in this issue of the BJP (Newens et al, 1995). This careful study describes the severe morbidity caused by the illness. Fifty-seven per cent of the sufferers were living at home. These were very damaged individuals who were seen infrequently by their family doctor, and who were receiving comparatively little support and help from the statutory services.

This study provides elegant confirmation that younger sufferers from Alzheimer's disease are not receiving the basic services that they require and are entitled to. This evidence is a firm pointer that the needs of these patients would be better served by a specialised dedicated service. The other important pieces of evidence come from two different sources. For several years it has been the consistent view of carers (Alzheimer's Disease Society, 1993) that there should be a specialist service for this group and an identified consultant with special responsibility for them. The third factor is linked to the future demand for definitive treatment for these patients. During the last ten years there has been considerable research activity into the development of drugs to retard or halt dementing conditions. Currently there is no consistent and enduring evidence that there is an effective drug for all patients with Alzheimer's disease (Byrne \& Arie, 1994). However, there are good reasons to think that eventually a therapeutic substance for this purpose will be discovered. Already clinicians are being asked by the carers of younger sufferers if something could be tried in case of an outside chance that it might be helpful. A specialised service would be well placed to introduce a new drug to this priority group.

Some thought has already been given to how specialised services of this nature should be provided. Newson-Smith (1983) made recommendations for services for the young brain-damaged. It should be based on a population of one million people, i.e. subregional and away from busy congested general hospitals. Facilities would be needed for both long and short-term patients, intermittent admissions and day patients. She emphasised spacious ground floor accommodations with gardens. Stout (1987) described the problem of providing these services in inner-city areas. Approaching the issue from another perspective, 
Priest \& Day (1990) recommended the idea that regional units for the 'young' brain-damaged should be based on existing mental hospital sites. These ideas resonate with the views of many clinicians. Although there are no guidelines to suggest the level of service provision that is required, in some areas ad hoc arrangements are being developed to improve the predicament of these patients. There would be relief among both carers and care givers if national guidelines were to be formulated about the most desirable services for younger sufferers with Alzheimer's disease. At present the Department of Health is unlikely to sponsor an initiative of this nature.

How is the matter to be taken forward? A major casualty of the deregulated Health Service is the disappearance of effective population-based planning mechanisms. Fortunately there are cogent reasons to think that these will emerge in the next series of re-organisations (Gray, 1995), but what should happen in the meantime? Fortunately, at this time there is good quality epidemiological work being done. Newens et al (1993) concluded from their work that in an average health district with a population of 60000 aged $45-64$, there will be about 20 patients with clinically diagnosed pre-senile dementia of Alzheimer type, and that for over half of these patients, hospital or community support will be required for more than five years.

In the current sea of changes, it is for professional people involved in the management of these patients and carers to collaborate to formulate guidelines for service provision. Old age psychiatrists have a good track record of developing new services for older sufferers of Alzheimer's disease. Some of these psychiatrists consider that services for the younger sufferers could be developed as a sub-department of an old age psychiatry service. In the absence of a Department of Health initiative, it seems appropriate for organisations such as the Royal College of Psychiatrists, the Royal College of Physicians and the Alzheimer's Disease Society, to come together to produce guidelines which will be the blueprint for service provision these tragic patients require.

\section{References}

Alzheimer's Disease Society (1993) The Younger Person with Dementia (Revised Edn). London: ADS.

BYrne, E. J. \& ARIE, T. (1994) Tetrahydroaminoacridine and Alzheimer's Disease. British Medical Journal, 308, 868-869.

GraY, J. (1995) The Reinvention of the NHS. The Guardian, 3rd January 1995, p. 16.

Newens, A. J., Forster, D. P., KAy, D. W. K., et al (1993) Clinically diagnosed pre-senile dementia of the Alzheimer type in the Northern Health Region: ascertainment, prevalence, incidence and survival. Psychological Medicine, 23, 631-644.

, Foster, D. P. \& KAY, D. W. K. (1995) Dependency and community care in pre-senile Alzheimer's Disease. British Journal of Psychiatry, 166, 777-782.

Newson-Smrth, J. (1983) Who cares for the adult brain damaged? Bulletin of The Royal College of Psychiatrists, 7, 181-183.

NHS Health Advisory Service (1992) The Rising Tide: Developing Services for Mental Illness in Old Age. Sutton, Surrey: NHS.

Priest, R. G. \& Day, K. A. (1990) The Future of Mental Hospital Sites. Psychiatric Bulletin, 14, 245-248.

Srout, I. H. (1987) Treatment of pre-senile dementia patients. Bulletin of the Royal College of Psychiatrists, 11, 312-313.

Dr D. D. R. Williams, FRCPsych, Cefn Coed Hospital, Swansea SA2 0GH. (Fax: 01792 580740)

(Received 18 January 1995, accepted 21 February 1995) 